\title{
Studying the Volatility of Pakistan Stock Exchange and Shanghai Stock Exchange Markets in the Light of CPEC: An Application of GARCH and EGARCH Modelling
}

\author{
Muhammad Ahsanuddin ${ }^{1}$, Tayyab Raza Fraz ${ }^{2}$, \\ Samreen Fatima ${ }^{2}$
}

\author{
${ }^{1}$ Department of Economics, University of Karachi, Pakistan \\ ${ }^{2}$ Department of Statistics, University of Karachi, Pakistan
}

\begin{abstract}
Globalization in the new millennium has brought a set of profound social, economic and political changes in the world. Pakistan and her neighboring country China have joined hands and has initiated ChinaPakistan Economic Corridor (CPEC) which is an ambitious project that focuses on improving connectivity and cooperation among both the neighboring giants. The growing nexus between China and Pakistan through CPEC is going to strengthen their markets as well stock markets. Ultimately both the economies are bound to benefit consequently resulting in increased GDP of both the countries. In this piece of research, we have studied the impact of CPEC on Pakistan Stock Market (PSX) and SSE by employing GARCH and EGARCH model from January 2011 to March 2019 on daily basis which shows recent purchases of up to $45 \%$ of Pakistani shares owned by China. Empirical analysis shows that in PSX risk parameter is little bit higher in post-CPEC comparatively pre-CPEC period. Volatility of SSE has high in both pre and post-CPEC period as compared to PSX. It reveals that PSX market after the advent of CPEC is showing stability which is a sign of encouragement for businessmen, traders and investors to invest. Market stability has increased manifold and the findings are supported by Morgan Stanley Capital International (MSCI). Recently Bloomberg has ranked Pakistan amongst the first 5 best performing stocks around the world. The research findings show PSX has a high potential for growth and is expected to become a lucrative market for businessmen, traders and investors.
\end{abstract}

Keywords: GARCH, EGARCH, CPEC, PSX, SSE

\section{Introduction}

A remarkable development plan initiated by the Chinese Government is the belt and road initiative alluded to the Silk Road Economic Belt and 21st Century Maritime Silk Road, that together termed One Belt One Road (OBOR). The purpose is to promote economic co-operation among countries involved in the planned Belt and Road routes as well to further market integration benefit to the region. One of six economic corridors of Silk Road Economic Belt is 3,218-kilometer-long route China-Pakistan Economic Corridor (CPEC) comprising of highways, railways and pipelines.

The estimated cost of this mega project is USD 75 billion which will be spent mainly on infrastructure development and energy generation. In addition, it is anticipated that this project will surge bilateral relationship between two countries to new heights and will transform the economy of Pakistan significantly. It is estimated that during the period 2015-2030 some 700,000 direct jobs will be created under CPEC project and will augment up to $2.5 \%$ points to the country's gross domestic product (GDP). If all the strategic projects are executed, the value of the projects would surpass all foreign direct investment (FDI) in Pakistan since 1970. International, national and local market often influence the rate of returns. The main source of profit earning from stock market are dividends. In addition, stocks, shares and bonds are traded by shareholders who gain by buying and selling them in secondary and tertiary markets. Rate of returns vary from market to market and risks are inherent in the trading. The amount of uncertainty or risk about the size of changes in a stock value projects stock market volatility. The lesser the volatility the stable the market and higher the growth rates.

This article is published under the terms of the Creative Commons Attribution License 4.0 Author(s) retain the copyright of this article. Publication rights with Alkhaer Publications. Published at: http://www.ijsciences.com/pub/issue/2019-03/

DOI: 10.18483/ijSci.2016; Online ISSN: 2305-3925; Print ISSN: 2410-4477 
The main objective of the study is to find the impact of CPEC projects on the volatility of Pakistan Stock Exchange (PSX) in connection with Shanghai Stock Exchange (SSE).

Rest of the paper is organized as follow: Section 2 consists of review of related studies. Section 3 deals brief introduction of GRACH and EGARCH models. Data analysis and experimental results are discussed in section 4. Conclusions are described in section 5 .

\section{Literature Review}

Lim \& Sek (2013) conducted an empirical study of Malaysian stock market using different GARCH models to identify the volatility of stock market. They used stock market data from January 1990 to December 2010 and divided the three-time parts of crises i.e. pre crises, during the crises and post crises. Their results reveal that two GARCH model types i.e. symmetric and asymmetric GARCH models have different performances with respect to the time phases. For pre and post-crises, symmetric GARCH model performs well. For crises period, asymmetric GARCH model is better. They also revealed that the rate of exchange and crude oil price play an important role on the Malaysia stock market volatility in the pre and post crises periods but there is no significant role of both exchange rate and crude oil on the stock market in the crises period. In another research Kovačić (2007) studied the behavior of stock returns and investigated the relationship between returns and conditional volatility. He used the daily closing market index MBI-10 i.e. Macedonian Stock Exchange form January 2005 to September 2007. He compared GARCH-M model, one symmetric (GARCH) and four asymmetric GARCH models namely TARCH, EGARCH, PGARCH and GJR. Furthermore, he used three distributions i.e. Student's t distribution, Gaussian, and Generalized Error Distribution. According to the findings, the Macedonian stock returns shows volatility clustering with high kurtosis. Also, leverage effect is present as according to all the asymmetric models. Lastly, GARCH models with non-Gaussian error distributions are (for in-sample and out-of-sample forecasting) found better as compare to other GARCH models included in the study.

Matei (2009) studied the forecasting techniques and superiority of advanced and complex models on the three daily selected indices namely DJIA, NASDAQ and S\&P from the period January 1980 to August 2008. He compared many time series models i.e. historical mean model, random walk model with drift, exponentially weighted moving average model and a simple regression model, moving average models and exponential smoothing model, standard GARCH models as well as two GJR-GARCH models. According to him, GARCH is the most appropriate model in the case of volatility evaluation for the returns of stocks with high frequency of time series data. Similarly, Alberg et al. (2008) compared the empirical analysis of the return by using the GARCH and other time series models. The conditional variance models are compared with asymmetric GJR and APARCH models. They used daily observations of Tel Aviv Stock Exchange (TASE) indices from October 1992 to May 2005. Their findings revealed that the EGARCH model using a skewed Student-t distribution is the most successful in forecasting the TASE indices.

Islam \& Mahkota (2013) worked on the stylized facts of Generalized Autoregressive Conditional Heteroscedasticity (GARCH) models. He used GARCH models to estimate the volatility of financial asset returns. In the study, he used Asian stock markets explicitly Jakarta Stock Exchange Composite Index (JKSE) of Indonesia, Kuala Lumpur Composite Index (KLCI) of Malaysia, and Straits Times Index (STI) of Singapore. He compared the symmetric GARCH and the GARCH-in-Mean models on the daily time period from January 2007 to December 2012. According to the results, there is a positive correlation which exist between the returns and risk for all markets. Nonetheless, only for Indonesian stock market, the estimated coefficient of risk premium is statistically significant while the risk-premium coefficients for other two markets are statistically insignificant. All the coefficients of risk premium are positive which shows the increase risk leads to a rise in the returns.

Chou (1988) investigated the volatility persistence and the changing risk premium in the stock market. He estimated the volatility and risk premium by the GARCH models. He used the weekly returns of the NYSE (New York stock exchange) from the period July 1962 to December 1985. According to the findings, the existence of equity changed premiums from 1962 to 1985 in the USA. The data did not reject non-stationary volatility process due to high fluctuation in stock return volatility. He compared the result with Malkiel (1979) \& Matei (2009) hypothesis and concludes that the unexpected investment increases the uncertainty during the time period of 1974 which is the reason behind the fall of stock market.

Lim \& Sek (2013) took the data of stock market in Malaysia from January 1990 to December 2010 to model the volatility in the stock market. They break 
the data into three parts as pre-crisis 1997, during crisis and post crisis 1997 . They used the class of GARCH models for modeling the volatility. The comparison of the performance of the models is measured by MSE, MAPE and RMSE. Their results suggested the symmetric GARCH models for the pre and post crisis period while asymmetric models for the fluctuation period or during crisis period.

Koima et al. (2015) discussed the stylized fact of volatility such as leverage effect, volatility clustering and fat tail distribution of Kenyan markets. Their findings described that Barclays Bank of Kenya was highly volatile.

Modeling volatility of DAX index GARCH process with skewed error distribution was used by Zhang (2009). Experimental result revealed that GARCH model with GED gave better performance. Babikir et al. (2012) used GARCH model with structural breaks to forecast volatility of South African Stock market. Their findings suggested that in out sample forecast Markov Switching-GARCH out performed than other studied GARCH models. Modeling and forecasting exchange rate volatility such as euro, pound, SwissFanc and yen on contrary of dollar GARCH $(1,1)$, Exponential EGARCH(1,1) and GJR(1,1) models were employed (Pilbeam \& Langeland, 2015). Empirical results depict that both in low and high volatility periods GRACH models achieved better forecast.

\section{Methodology}

\subsection{GARCH model}

To model volatility, Engel (1982) proposed Auto Regressive Conditional Heteroscedasticity

(ARCH). After some time, Bollerslev (1986) provided a valuable extension known as Generalized Auto Regressive Conditional Heteroscedasticity (GARCH).

For percentage of log return series, the mean equation is described as,

$$
\log \vartheta_{t}=\tau_{o}+\sum_{i=1}^{n} \tau_{i}\left(\frac{\left|b_{t-i}\right|}{\sqrt{\vartheta_{t-i}^{2}}}-\sqrt{\frac{2}{\pi}}\right)+\sum_{j=1}^{m} \varpi_{i} \frac{b_{t-i}}{\sqrt{\vartheta_{t-j}^{2}}}+\sum_{j=1}^{m} \lambda_{j} \log \vartheta_{t-j}
$$

Where, the coefficient $\lambda_{\mathrm{j}}$ measures the persistence in conditional volatility (Alexander, 2009).

For the large value of $\lambda_{j}$ it takes a longer time frame to vanish under a market impasse and viceversa (Alexander \& Lazar, 2004). Whereas, $\varpi_{\mathrm{i}}$ measure leverage effect, for $\varpi_{\mathrm{i}}=0$, leverage effect is zero, if $\varpi_{\mathrm{i}}<0$, designates that adverse news has added effect than positive news while
Where,

$$
r_{\mathrm{t}}=\mu_{\mathrm{t}}+b_{\mathrm{t}}
$$

$$
b_{\mathrm{t}}=r_{\mathrm{t}}-\mu_{\mathrm{t}}
$$

The GARCH $(m, n)$ model is explained as the weighted sum of condition lagged variance and weighted past squared of mean-corrected series.

$$
\vartheta_{\mathrm{t}}=\tau_{0}+\sum_{\mathrm{i}=1}^{\mathrm{n}} \tau_{\mathrm{i}} b_{\mathrm{t}-\mathrm{i}}^{2}+\sum_{\mathrm{j}=1}^{\mathrm{m}} \lambda_{\mathrm{j}} \vartheta_{\mathrm{t}-\mathrm{j}}
$$

Where $n \geq 0, m>0, \tau_{0}>0, \tau_{\mathrm{i}} \geq 0, \mathrm{i}=1, \ldots$ . $\mathrm{m}, \lambda_{\mathrm{j}} \geq 0, \mathrm{j}=1, \ldots, \mathrm{n}$

Equation (1) shows that large past mean-corrected squared returns $b_{\mathrm{t}-\mathrm{i}}^{2}$ or lagged conditional variances $\vartheta_{\mathrm{t}-\mathrm{j}}$ or both offer increase in $\vartheta_{\mathrm{t}}$.

In GARCH model, the sum of the coefficient $b_{\mathrm{t}-\mathrm{i}}^{2}$ and $\vartheta_{\mathrm{t}-\mathrm{j}}^{2}, \tau_{\mathrm{i}}+\lambda_{\mathrm{j}}<1$ refers the $\operatorname{GARCH}(m, n)$ is stationary. Whereas, $\tau_{\mathrm{i}}+\lambda_{\mathrm{j}}>1$ the process is non-stationary in variance.

\subsection{EGARCH (Exponential GARCH) model}

Simple GARCH model has some weaknesses, it cannot explain asymmetry or leverage effect. In 1991, Nelson explained that negative shock has much larger effect on volatility as compared to positive shock of similar magnitude. An exponential GARCH (EGARCH) model which explained leverage effect is a logarithmic expression of the conditional variability in the variable under analysis which depends on both size and the sign of the lagged residuals.

The above left-hand side equation is a logarithmic expression of the conditional variance.

$\operatorname{EGARCH}(m, n)$ model is described as,

$\varpi_{\mathrm{i}}>0$, positive information has more effect than negative evidence.

\section{Data analysis}

In this research work we utilized daily closing price data of Pakistan's KSE-100 and China's SSE stock markets from January 1, 2011 till March 7, 2019 obtained from www.investing.com. As the China Pakistan Economic Corridor (CPEC) agreements were signed on April 20, 2015, therefore data is divided into pre-CPEC from January 1, 2011 to 
Studying the Volatility of Pakistan Stock Exchange and Shanghai Stock Exchange Markets in the Light of CPEC: An Application of GARCH and EGARCH Modelling

April 20, 2015 and post-CPEC from April 20, 2015, to March 7, 2019. The dataset contains 2225 observations for each country. It is conducive for both the markets to have same weekly public holidays i.e. Saturday and Sunday. If trading suspends say for a given day the consecutive day's trading starts with the last day's closing price. Therefore, missing observations were adjusted with the previous day's closing value. Figure1 (a) and 1(b) show daily closing price and percentage of logarithmic returns series of KSE-100.

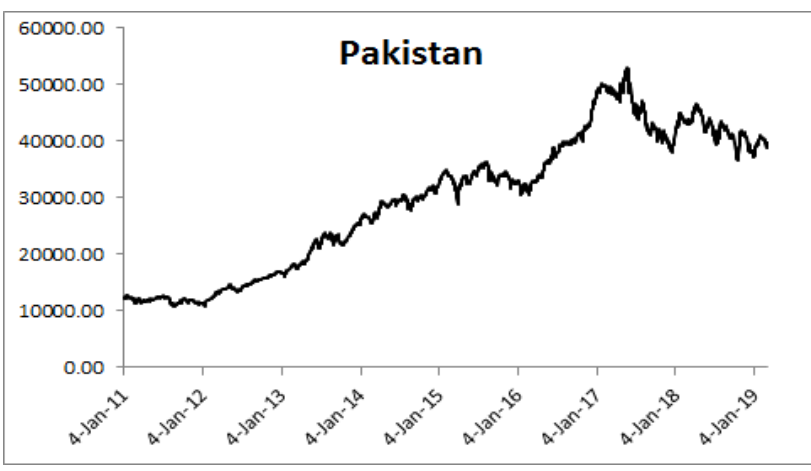

Figure 1(a): daily closing price of KSE-100

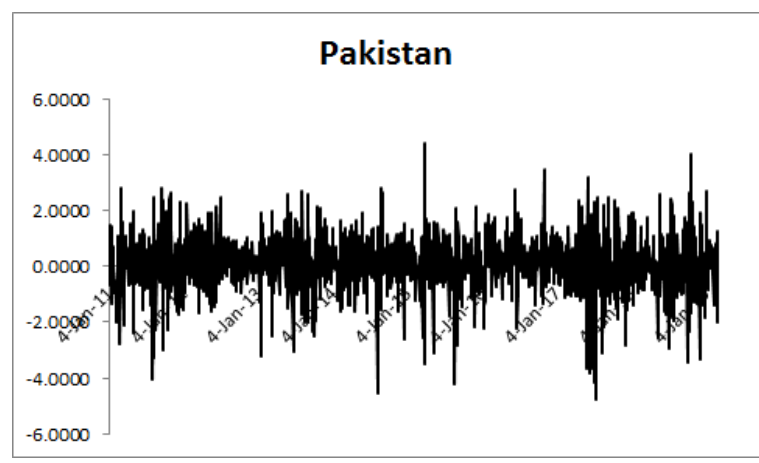

Figure 1(b): Percentage of logarithmic returns of KSE-100

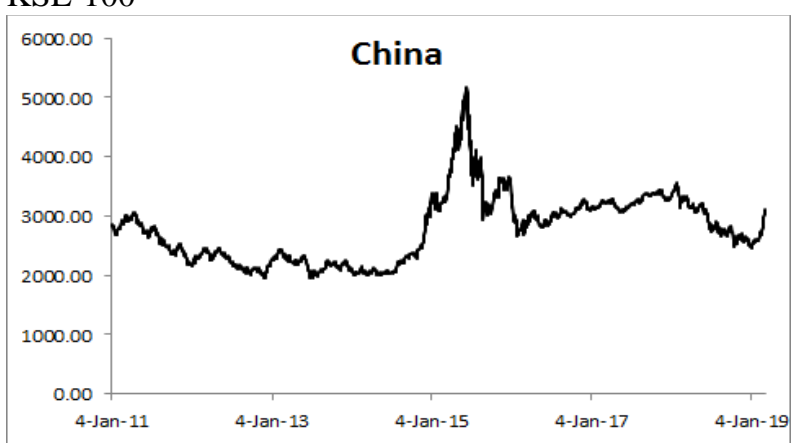

Figure 2(a): daily closing price of SSE

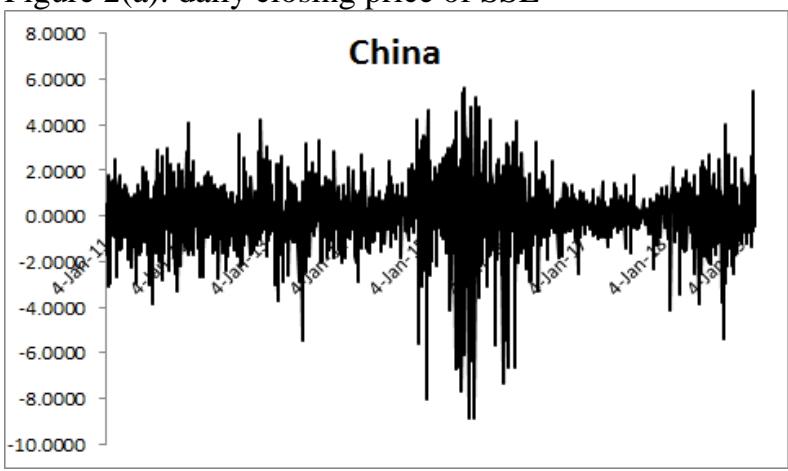

Figure 2(b): Percentage of Logarithmic returns of SSE

Figure 2(a) and 2(b) show daily closing price and logarithmic returns series of SSE.

Figure1(a), depicts daily closing price gradually increases from beginning to till June 5, 2015, then decreases up to January 13, 2016. Whereas, Figure 1(b) shows January 9, 2014 to March 30, 2016 is a highly volatile period. Figure 2(a) exhibits increasing trend from the beginning to May 7, 2017. Figure 2(b) displays high and low fluctuation periods evenly distributed.

Table 1: Descriptive Statistics of returns of pre-CPEC and post-CPEC

\begin{tabular}{|l|r|r|r|r|}
\hline \multicolumn{2}{|c|}{ Pre-CPEC: Jan. 1, 2011-April 20, 2015 } & \multicolumn{2}{|l|}{ Post-CPEC: April 21, 2015, to March 7, 2019 } \\
\hline & DLOG(CH) & DLOG(PK) & DLOG(CH) & \multicolumn{2}{|l|}{ DLOG(PK) } \\
\hline Mean & 0.0351 & 0.0908 & -0.0321 & 0.0180 \\
\hline Median & 0.0000 & 0.0679 & 0.0159 & 0.0000 \\
\hline Maximum & 4.6358 & 4.4186 & 5.6036 & 4.0434 \\
\hline Minimum & -8.0174 & -4.5580 & -8.8729 & -4.7650 \\
\hline Std. Dev. & 1.1476 & 0.8767 & 1.5107 & 0.9526 \\
\hline Skewness & -0.2847 & -0.3422 & -1.2639 & -0.3799 \\
\hline Kurtosis & 6.9045 & 5.8538 & 10.4742 & 5.7654 \\
\hline Jarque-Bera & 722.6754 & 399.7602 & 2612.0560 & 345.0926 \\
\hline Probability & 0.0000 & 0.0000 & 0.0000 & 0.0000 \\
\hline Observations & 1114 & 1114 & 1007 & 1007 \\
\hline
\end{tabular}

Table1, shows that average returns of KSE-100 are positive both in pre-CPEC and post-CPEC period whereas SSE has positive value in pre-CPEC and negative in post-CPEC period. Standard deviation 
Studying the Volatility of Pakistan Stock Exchange and Shanghai Stock Exchange Markets in the Light of CPEC: An Application of GARCH and EGARCH Modelling

of China widely increases therefore volatility is high in SSE for both pre and post CPEC period as compared to KSE-100. The kurtosis of the daily returns greater than 3 in all pre and post periods indicate returns have leptokurtic distribution. Skewness of both markets are negative which can be confirmed by the Jarqe-Bera test.

ARCH-LM test is performed to test the heteroscedasticity.
$\mathrm{H}_{0}$ : Heteroscedasticity is not present.

$\mathrm{H}_{\mathrm{a}}$ : Heteroscedasticity is present.

Table 2 shows output of ARCH -LM test, which indicates that the null hypothesis is rejected at $5 \%$ level of significance. Consequently, the series under consideration have ARCH/GARCH effect.

Table 2(a): Output of ARCH-LM, Pre-CPEC

\begin{tabular}{|l|c|c|c|}
\hline \multicolumn{4}{|c|}{ ARCH test-SSE } \\
\hline F-statistic & 39.7 & Prob. F(5,998) & 0 \\
\hline $\mathrm{T}^{*} \mathrm{R}^{2}$ & 116.87 & Prob. Chi-S(5) & 0 \\
\hline \multicolumn{4}{|c|}{ ARCH test-KSE-100 } \\
\hline F-statistic & 7 & Prob. F(5,998) & 0 \\
\hline $\mathrm{T}^{*} \mathrm{R}^{2}$ & 37 & Prob. Chi-S(5) & 0 \\
\hline
\end{tabular}

Table 2(b): Output of ARCH-LM, Post-CPEC

\begin{tabular}{|l|c|c|c|}
\hline \multicolumn{5}{|c|}{ ARCH test-SSE } \\
\hline F-statistic & 14.34 & Prob. F(5,1103) & 0 \\
\hline $\mathrm{T}^{*} \mathrm{R}^{2}$ & 54.79 & Prob. Chi-S $(5)$ & 0 \\
\hline \multicolumn{5}{|c|}{ ARCH test-KSE-100 } \\
\hline F-statistic & 11.84 & Prob. F(5,1103) & 0 \\
\hline $\mathrm{T}^{*} \mathrm{R}^{2}$ & 56.52 & Prob. Chi-S(5) & 0 \\
\hline
\end{tabular}

Table 3: Parameter estimates of GARCH $(1,1)$ model of SSE and KSE-100

\begin{tabular}{|c|c|c|c|c|}
\hline \multicolumn{5}{|c|}{ SSE-Pre-CPEC } \\
\hline Parameter & Values & S. E & Z.Stat & Prob. \\
\hline $\mathrm{k}$ & 0.0177 & 0.0324 & 0.5464 & 0.5848 \\
\hline \multicolumn{5}{|c|}{ GARCH-EQ } \\
\hline$\tau_{0}$ & 0.0309 & 0.0100 & 3.1048 & 0.0019 \\
\hline$\tau_{1}$ & 0.0395 & 0.0069 & 5.7153 & 0.0000 \\
\hline$\lambda_{1}$ & 0.9375 & 0.0127 & 74.0342 & 0.0000 \\
\hline \multicolumn{5}{|c|}{ SSE-Post- CPEC } \\
\hline $\mathrm{k}$ & 0.0085 & 0.0276 & 0.3085 & 0.7577 \\
\hline \multicolumn{5}{|c|}{ GARCH-EQ } \\
\hline$\tau_{0}$ & 0.0046 & 0.0013 & 3.3939 & 0.0007 \\
\hline$\tau_{1}$ & 0.0579 & 0.0059 & 9.7640 & 0.0000 \\
\hline$\lambda_{1}$ & 0.9419 & 0.0046 & 205.0941 & 0.0000 \\
\hline \multicolumn{5}{|c|}{ KSE-100-Pre-CPEC } \\
\hline $\mathrm{k}$ & 0.1428 & 0.0256 & 5.5778 & 0.0000 \\
\hline \multicolumn{5}{|c|}{ GARCH-EQ } \\
\hline$\tau_{0}$ & 0.0741 & 0.0159 & 4.6535 & 0.0000 \\
\hline$\tau_{1}$ & 0.1747 & 0.0259 & 6.7578 & 0.0000 \\
\hline$\lambda_{1}$ & 0.7403 & 0.0376 & 19.6825 & 0.0000 \\
\hline \multicolumn{5}{|c|}{ KSE-100-Post- CPEC } \\
\hline $\mathrm{k}$ & 0.0652 & 0.0283 & 2.3036 & 0.0212 \\
\hline \multicolumn{5}{|c|}{ GARCH-EQ } \\
\hline$\tau_{0}$ & 0.0560 & 0.0103 & 5.4271 & 0.0000 \\
\hline$\tau_{1}$ & 0.1242 & 0.0155 & 8.0007 & 0.0000 \\
\hline$\lambda_{1}$ & 0.8186 & 0.0180 & 45.4840 & 0.0000 \\
\hline
\end{tabular}

Notes: GARCH $(1,1)$ model, $\vartheta_{t}=\tau_{0}+\tau_{1} b_{t-1}^{2}+\lambda_{1} \vartheta_{t-1}$

Table 2, reports estimation results of KSE-100 and SSE. The parameters under consideration have zero p-value, signifying that together the past shock and past variance coefficients terms are found to be significant at $5 \%$ level. The sum of coefficients of $\tau_{1}+\lambda_{1}$ has 0.96 (SSE-Pre-CPEC), 0.99 (SSEPost-CPEC), 0.91 (KSE-100-Pre-CPEC) and 0.93 (KSE-100-Post-CPEC) respectively which shows SSE and KSE-100 are stationary in Pre and Post CPEC periods. Moreover, the value of GARCH coefficients of KSE-100 is less than SSE indicating $\mathrm{KSE}-100$ is less persistent that SSE. 
Studying the Volatility of Pakistan Stock Exchange and Shanghai Stock Exchange Markets in the Light of CPEC: An Application of GARCH and EGARCH Modelling

Table 3: Parameter estimates of EGARCH $(1,1)$ model of SSE and KSE-100

\begin{tabular}{|c|c|c|c|c|}
\hline \multicolumn{5}{|c|}{ SSE-Pre-CPEC } \\
\hline Parameter & Values & S. E & Z. Stat & Prob. \\
\hline$r_{t-1}$ & 0.0259 & $\begin{array}{r}0.032 \\
5 \\
\end{array}$ & 0.7956 & $\begin{array}{r}0.426 \\
3 \\
\end{array}$ \\
\hline \multicolumn{5}{|c|}{ GARCH-EQ } \\
\hline$\tau_{0}$ & $0.0602^{-}$ & $\begin{array}{r}0.010 \\
7 \\
\end{array}$ & -5.6078 & $\begin{array}{r}0.000 \\
0 \\
\end{array}$ \\
\hline$\left|b_{t-1}\right| / \sqrt{\vartheta_{t-1}}$ & 0.0898 & $\begin{array}{r}0.015 \\
0 \\
\end{array}$ & 5.9769 & $\begin{array}{r}0.000 \\
0 \\
\end{array}$ \\
\hline$b_{\mathrm{t}-1} / \sqrt{\vartheta_{\mathrm{t}-1}}$ & 0.0065 & $\begin{array}{r}0.006 \\
4 \\
\end{array}$ & 1.0074 & $\begin{array}{r}0.313 \\
7 \\
\end{array}$ \\
\hline $\log \vartheta_{t-1}$ & 0.9856 & $\begin{array}{r}0.006 \\
0 \\
\end{array}$ & $\begin{array}{r}165.161 \\
9 \\
\end{array}$ & $\begin{array}{r}0.000 \\
0 \\
\end{array}$ \\
\hline \multicolumn{5}{|c|}{ SSE-Post-CPEC } \\
\hline$r_{\mathrm{t}-1}$ & 0.0149 & $\begin{array}{r}0.024 \\
8 \\
\end{array}$ & 0.5999 & $\begin{array}{r}0.548 \\
6 \\
\end{array}$ \\
\hline \multicolumn{5}{|c|}{ GARCH-EQ } \\
\hline$\tau_{0}$ & $\begin{array}{r}- \\
0.0795 \\
\end{array}$ & $\begin{array}{r}0.007 \\
3 \\
\end{array}$ & $\begin{array}{r}- \\
10.9472 \\
\end{array}$ & $\begin{array}{r}0.000 \\
0 \\
\end{array}$ \\
\hline$\left|b_{t-1}\right| \mid$ & 0.1135 & $\begin{array}{r}0.010 \\
6 \\
\end{array}$ & 10.6585 & $\begin{array}{r}0.000 \\
0 \\
\end{array}$ \\
\hline$b_{\mathrm{t}-1} / \sqrt{\vartheta_{\mathrm{t}-1}}$ & $0.0022^{-}$ & $\begin{array}{r}0.008 \\
5 \\
\end{array}$ & -0.2634 & $\begin{array}{r}0.792 \\
3 \\
\end{array}$ \\
\hline $\log \vartheta_{\mathrm{t}-1}$ & 0.9971 & $\begin{array}{r}0.001 \\
3 \\
\end{array}$ & $\begin{array}{r}773.432 \\
9 \\
\end{array}$ & $\begin{array}{r}0.000 \\
0\end{array}$ \\
\hline \multicolumn{5}{|c|}{ KSE-100-Pre-CPEC } \\
\hline$r_{\mathrm{t}-1}$ & 0.1264 & $\begin{array}{r}0.022 \\
5 \\
\end{array}$ & 5.6087 & $\begin{array}{r}0.000 \\
0 \\
\end{array}$ \\
\hline \multicolumn{5}{|c|}{ GARCH-EQ } \\
\hline$\tau_{0}$ & $\begin{array}{r}- \\
0.2811 \\
\end{array}$ & $\begin{array}{r}0.035 \\
5 \\
\end{array}$ & -7.9280 & $\begin{array}{r}0.000 \\
0 \\
\end{array}$ \\
\hline$\left|b_{t-1}\right| / \sqrt{\vartheta_{t-1}}$ & 0.2993 & $\begin{array}{r}0.038 \\
7 \\
\end{array}$ & 7.7287 & $\begin{array}{r}0.000 \\
0 \\
\end{array}$ \\
\hline$b_{t-1} / \sqrt{\vartheta_{t-1}}$ & $\begin{array}{r}- \\
0.1867 \\
\end{array}$ & $\begin{array}{r}0.022 \\
2 \\
\end{array}$ & -8.4043 & $\begin{array}{r}0.000 \\
0 \\
\end{array}$ \\
\hline $\log \vartheta_{t-1}$ & 0.8820 & $\begin{array}{r}0.021 \\
2 \\
\end{array}$ & 41.6742 & $\begin{array}{r}0.000 \\
0 \\
\end{array}$ \\
\hline \multicolumn{5}{|c|}{ KSE-100-Post-CPEC } \\
\hline$r_{t-1}$ & 0.0368 & $\begin{array}{r}0.026 \\
8 \\
\end{array}$ & 1.3748 & $\begin{array}{r}0.169 \\
2 \\
\end{array}$ \\
\hline \multicolumn{5}{|c|}{ GARCH-EQ } \\
\hline$\tau_{0}$ & $\begin{array}{r}- \\
0.1591\end{array}$ & $\begin{array}{r}0.017 \\
3 \\
\end{array}$ & -9.2022 & $\begin{array}{r}0.000 \\
0 \\
\end{array}$ \\
\hline & 0.1880 & $\begin{array}{r}0.023 \\
1 \\
\end{array}$ & 8.1297 & $\begin{array}{r}0.000 \\
0 \\
\end{array}$ \\
\hline
\end{tabular}

\begin{tabular}{|l|r|r|r|r|}
$\left|b_{\mathrm{t}-1}\right| / \sqrt{\vartheta_{\mathrm{t}-1}}$ & & & & \\
\hline & & & & \\
$b_{\mathrm{t}-1} / \sqrt{\vartheta_{\mathrm{t}-1}}$ & 0.1495 & 0.016 & & 0.000 \\
\hline $\log \vartheta_{\mathrm{t}-1}$ & 0.9402 & 0.008 & 105.856 & 0.000 \\
\hline
\end{tabular}

Notes:

$\log \vartheta_{\mathrm{t}}=\tau_{0}+\tau_{1}\left(\frac{\left|b_{\mathrm{t}-1}\right|}{\sqrt{\vartheta_{\mathrm{t}-1}}}-\sqrt{\frac{2}{\pi}}\right)+\varpi_{1} \frac{b_{\mathrm{t}-1}}{\sqrt{\vartheta_{\mathrm{t}-1}}}+\lambda_{1} \log \vartheta_{\mathrm{t}-1}$

Table 3 illustrates that in leverage effect is observed in both markets. KSE-100 has is high leverage effected both in pre and post-CPEC. SSE has positive leverage effect in pre-CPEC and negative in post- CPEC indicates leverage effect has increased in post-CPEC period.

\section{Conclusion:}

This study compared the volatility and leverage effect of PSX and SSE in the perspective of CPEC. The data from January 1, 2011, to April 20, 2015 was used as pre-CPEC and April 21, 2019 considered as post-CPEC period. GARCH and EGARCH models are used to measure sensitivity, persistency and leverage effect of PSX and SSE stock markets. It was observed that the parameter of past conditional volatility has increased in postCPEC of both the markets but the PSX is more stable than SSE. Moreover, leverage effect was present in both the markets. Pre-CPEC period has greater leverage effect than post-CPEC period for PSX. On other hand, post-CPEC period has high leverage effect as compared to pre-CPEC period for SSE. The study also shows that CPEC has positive impact on Pakistan Stock Exchange as compared to Shanghai Stock Exchange. Since PSX has low volatility, the market stability offers better opportunities for traders and investors. CPEC is a game changer and is expected to bring boom for the economy of Pakistan and adjoining economies as well. Countries like Saudi Arabia has shown interest in investing in the markets of Pakistan and has already committed USD 20 billion in energy and chemical industry projects in Gwadar Port which is a part of CPEC.

\section{References:}

1. Alberg, Dima, Shalit, Haim, \& Yosef, Rami. (2008). Estimating stock market volatility using asymmetric GARCH models. Applied Financial Economics, 18(15), 1201-1208.

2. Alexander, Carol. (2009). Market Risk Analysis, Value at Risk Models (Vol. 4): John Wiley \& Sons.

3. Alexander, Carol, \& Lazar, Emese. (2004). The equity index skew, market crashes and asymmetric normal 
mixture GARCH. ISMA Centre discussion papers in Finance, 14.

4. Babikir, Ali, Gupta, Rangan, Mwabutwa, Chance, \& Owusu-Sekyere, Emmanuel. (2012). Structural breaks and GARCH models of stock return volatility: The case of South Africa. Economic Modelling, 29(6), 2435-2443.

5. Bollerslev, T. (1986). Generalized autoregressive conditional heteroskedasticity. Journal of econometrics, 31(3), 307-327.

6. Chou, Ray Yeutien. (1988). Volatility persistence and stock valuations: Some empirical evidence using GARCH. Journal of Applied Econometrics, 3(4), 279-294.

7. Engle, R. F. (1982). Autoregressive conditional heteroscedasticity with estimates of the variance of United Kingdom inflation. Econometrica: Journal of the Econometric Society, 987-1007.

8. Islam, Mohd Aminul, \& Mahkota, BI. (2013). Estimating volatility of stock index returns by using symmetric GARCH models. Middle-East Journal of Scientific Research, 18(7), 991-999.

9. Koima, JK, Mwita, PN, \& Nassiuma, DK. (2015). Volatility estimation of stock prices using Garch method.
10. Kovačić, Zlatko. (2007). Forecasting volatility: Evidence from the Macedonian stock exchange.

11. Lim, Ching Mun, \& Sek, Siok Kun. (2013). Comparing the performances of GARCH-type models in capturing the stock market volatility in Malaysia. Procedia Economics and Finance, 5, 478-487.

12. Malkiel, Burton G. (1979). The capital formation problem in the United States. The Journal of Finance, 34(2), 291306

13. Matei, Marius. (2009). Assessing volatility forecasting models: why GARCH models take the lead. Romanian Journal of Economic Forecasting, 12(4), 42-65.

14. Nelson, D. B. (1991). Conditional heteroskedasticity in asset returns: A new approach. Econometrica: Journal of the Econometric Society, 347-370.

15. Pilbeam, Keith, \& Langeland, Kjell Noralf. (2015) Forecasting exchange rate volatility: GARCH models versus implied volatility forecasts. International Economics and Economic Policy, 12(1), 127-142.

16. Zhang, Ziqi. (2009). Analysis Skewness in GARCH model. School of Economics and Social Sciences, Høgskolan

Dalarna. 